\title{
Dietary intake of linoleic acid in multiple sclerosis and other diseases
}

\author{
NOEL CALLAGHAN, BRID KEARNEY, AND WILLIAM CLAYTON LOVE ${ }^{1}$ \\ From the Departments of Neurology, Dietetics, and Clinical Biochemistry, \\ St. Finbarr's Hospital, Cork, Ireland.
}

SUMmARY The linoleic acid intake of patients with multiple sclerosis is not significantly different from that of healthy control subjects. This is true both in absolute terms and when linoleic acid intake is expressed as a percentage of total fat intake. In the other categories of illness, included as control groups, linoleic acid intake was significantly decreased only in patients with acute non-neurological illness and in this case only when considered in absolute terms. In all groups studied the daily linoleic acid intake was in excess of $1.7 \%$ of the total calorie intake and in the case of multiple sclerosis was $2.7 \%$ of the total calories ingested. Since other workers have shown that linoleic acid absorption is not altered in multiple sclerosis and we have shown that the diet is not deficient, it seems that the decrease in linoleic acid content is due to some process occurring after the absorption of this essential fatty acid.

The prevalence of multiple sclerosis varies in different parts of the world with high risk zones occurring in the northern hemisphere, between latitudes $47^{\circ}$ and $60^{\circ}$ in Europe, and north of latitude $40^{\circ}$ in North America (McAlpine, Lumsden, and Acheson, 1965). While it is possible that this variation with latitude reflects the effects of climate and other environmental factors, an interesting observation was made-the difference in dietary habits with special reference to fat intake. Swank $(1950,1956)$ stated that the fat intake in high risk zones was above $100 \mathrm{~g}$ daily and below $50 \mathrm{~g}$ daily in low risk zones. Observations in Norway, Denmark, and Holland showed a decrease in the number of patients with multiple sclerosis admitted to hospital during the war years, when the amount of fat available was restricted (Swank, 1950). An increase in the dietary fat available in Norway and Denmark immediately after the war was associated with an increase in the number of multiple sclerosis patients admitted to hospital. Swank, Lerstad, Strøm, and Backer (1952) stated that the high incidence of multiple sclerosis in farming areas of Norway compared with coastal areas was

\footnotetext{
Present address: Clinical Biochemistry Laboratory, Biochemistry Department, Trinity College, Dublin 2.
} 
mal subjects (Belin, Pettet, Smith, Thompson, and Zilkha 1971). It has been suggested that altered levels of linoleic acid could be related to either an increase in the intake of saturated fats or reduction in the intake of unsaturated fats in the diet (Thompson, 1966). Dietary studies in multiple sclerosis relating linoleic acid intake with altered levels of linoleic acid in the serum have not been reported previously. In order to clarify this point we set up a quantitative dietary survey in a group of multiple sclerosis patients. Simultaneously with this dietary study the linoleic acid and fatty acid pattern of plasma lipids was investigated and a preliminary report has been published (Love, Cashell, Reynolds, and Callaghan, 1972).

\section{METHODS}

We assessed 102 subjects in the dietary study. These included patients with multiple sclerosis of varying activity and three control groups comprising patients with neurological diseases other than multiple sclerosis, patients with acute non-neurological illnesses, and healthy subjects.

MULTIPLE SCLEROSIS PATIENTS Group $A$ This consisted of 11 patients (five males and six females), with a mean age of 35 years. These patients were seen during acute exacerbations of the disease, but their incapacity before the acute exacerbation was minimal and did not interfere with their normal daily activities.

Group $B$ This group consisted of 16 cases (seven males and nine females), with a mean age of 38 years. They showed progressive deterioration due to disease to the extent that it interfered with normal daily activities, but they were not confined to bed or to a wheelchair.

Group $C$ This group consisted of 14 cases (eight males and six females), with a mean age of 32 years who were permanently confined to bed or to a wheelchair.

CONTROL GROUPS Three control groups were included in the study; these were divided as follows:

Neurological controls There were 21 patients (14 males and seven females) with a mean age of 40 years, suffering from neurological diseases other than multiple sclerosis (Table 1).
TABLE 1

NEUROLOGICAL CONTROLS-COMPOSITION OF GROUP

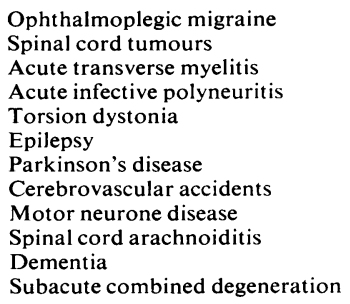

Acute non-neurological controls Twenty patients with acute non-neurological illness (12 females and eight males), with a mean age of 50 years (Table 2) formed a second group.

Healthy controls Twenty healthy controls (12 males and eight females) with a mean age of 30 years were also studied. The healthy controls were selected from army personnel and hospital staff.

PROCEDURE The dietary intake was studied by the recall method. In each case a dietary history was taken by the same dietitian using a detailed questionnaire at one interview lasting approximately 45 minutes. Taking the previous week's diet as a basis, a record was made of an average daily intake. In the case of hospitalized patients, diet was assessed on the basis of the food intake after one week of hospitalization. In the case of hospitalized patients and patients taking their food in canteens, the dietary menus were checked in order to test the reliability of the subject's dietary history. With the exception of seven in group B and eight in group $\mathrm{C}$ of the multiple sclerosis patients, all of the other patients were studied as inpatients in hospital. The army personnel and hospital staff ate most of their food in a canteen. The dietary questionnaire was phrased in different

TABLE 2

ACUTE NON-NEUROLOGICAL DISEASES - CONTROL GROUP

\begin{tabular}{lc} 
Diagnosis & $\begin{array}{c}\text { Number of } \\
\text { patients }\end{array}$ \\
\hline Acute respiratory infections & 7 \\
Rheumatoid arthritis & 2 \\
Myocardial infarction & 3 \\
Severe anaemia & 3 \\
Peptic ulceration & 2 \\
Carcinoma of lung & 2 \\
Thyrotoxicosis & 1 \\
\hline
\end{tabular}


ways in order to test the reliability of the patient. Any subject who was thought not to be reliable was discarded from the study.

Special food tables were compiled for the study. Food tables were based on data given in the food tables prepared by (McCance and Widdowson, 1960) and, for the purpose of assessing linoleic acid intake, the Agricultural Handbook No. 8 of the Agricultural Research Service, United States Department of Agriculture (Watt and Merrill, 1963). Details of some locally produced foods were obtained from the manufacturers. The food tables were prepared in conjunction with the Department of Computer Science, University College, Cork, who programmed the survey for processing by computer. Student's $t$ test was used to compare differences between means. Results were regarded as significant only when $P$ values were 0.01 or less.

\section{RESULTS}

Table 3 shows the intake of total fat, saturated fatty acids, and unsaturated fatty acids. There was a significant reduction in the intake in all ill patients when compared with healthy controls. The lowest intake was found in acute nonneurological illness. No significant difference was found when the intake in multiple sclerosis patients was compared with acute non-neurological illness and with neurological controls. No significant difference was found when neurological controls were compared with acute nonneurological illness.

TABLE 3

MEAN DAILY INTAKE OF FATS FOR ALL GROUPS STUDIED $($ MEAN \pm SEM)

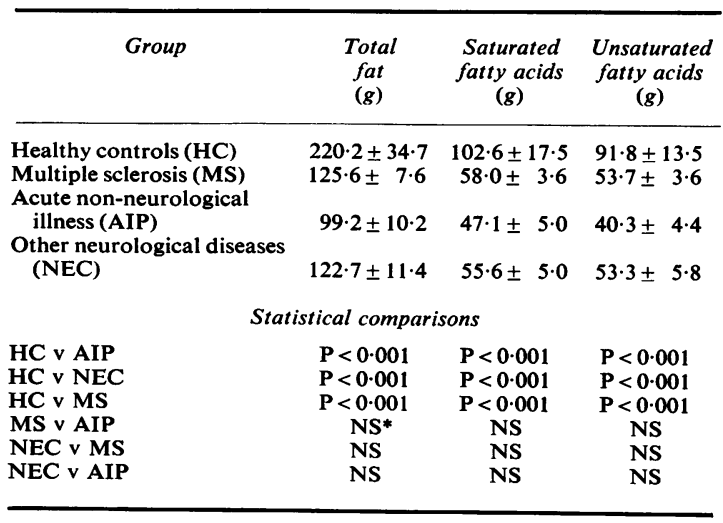

* NS = not statistically significant.
The intake of saturated fats was at a higher level than unsaturated fats in all three groups, the greatest difference was in healthy subjects.

Table 4 shows the intake of total fat, saturated and unsaturated fatty acids in various grades of multiple sclerosis. The highest intake was found in people admitted with acute exacerbations of

TABLE 4

DAILY INTAKE OF FATS IN MULTIPLE SCLEROSIS IN RELATION TO ACTIVITY OF THE DISEASE

$($ MEAN \pm SEM)

\begin{tabular}{cccc}
\hline Group & $\begin{array}{c}\text { Total } \\
\text { fat } \\
(g)\end{array}$ & $\begin{array}{c}\text { Saturated } \\
\text { fatty acids } \\
(\mathrm{g})\end{array}$ & $\begin{array}{c}\text { Unsaturated } \\
\text { fatty acids } \\
(\mathrm{g})\end{array}$ \\
\hline A & $148 \cdot 2 \pm 17 \cdot 1$ & $\mathbf{6 8 \cdot 2} \pm \mathbf{8 \cdot 0}$ & $\mathbf{6 4 \cdot 3} \pm \mathbf{8} \cdot 5$ \\
B & $125 \cdot 3 \pm 11 \cdot 2$ & $58 \cdot 9 \pm 5 \cdot 7$ & $53 \cdot 7 \pm 5 \cdot 4$ \\
C & $108 \cdot 2 \pm 11 \cdot 1$ & $49 \cdot 1 \pm 5 \cdot 2$ & $45 \cdot 2 \pm 5 \cdot 1$ \\
& & & \\
A v B & NS & NS & NS \\
B v C & NS & NS & NS \\
A v C & NS & NS & NS \\
\hline
\end{tabular}

the disease, and the lowest intake was found in patients permanently confined to bed or to a wheelchair. Although patients with acute exacerbations were confined to bed when the study was carried out, the higher intake was probably related to the fact that their activities were not restricted to a great extent before admission to hospital; the lower intake in the other two groups was possibly related to prolonged periods of progressive inactivity.

Table 5 shows the daily intake of linoleic acid in the various groups studied. In addition, linoleic acid intake is expressed as a percentage of both total and unsaturated fats. When compared with healthy controls the only group with a statistically significant reduction in linoleic acid intake were those with acute non-neurological illness. The intake of linoleic acid as a percentage of total fat and of unsaturated fatty acids was not significantly different in healthy controls from that of the ill patients group.

Table 6 shows the intake of linoleic acid and the linoleic acid as a percentage of total fat and unsaturated fatty acids in multiple sclerosis during various phases of activity of the disease. No significant difference was found in the intake 
TABLE 5

DAILY LINOLEIC ACID INTAKE

$(M E A N \pm S E M)$

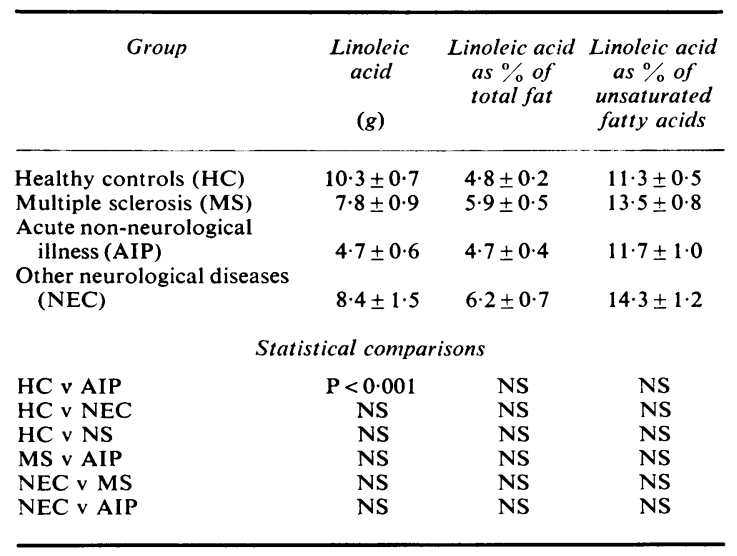

TABLE 6

LINOLEIC ACID INTAKE IN MULTIPLE SCLEROSIS IN RELATION TO ACTIVITY OF THE DISEASE (MEAN \pm SEM)

\begin{tabular}{cccc}
\hline Group & $\begin{array}{c}\text { Linoleic } \\
\text { acid } \\
(\mathrm{g})\end{array}$ & $\begin{array}{c}\text { Linoleic acid as } \\
\% \text { of total fat } \begin{array}{c}\text { Linoleic acid as } \\
\%\end{array} \\
\text { ted fansatura- }\end{array}$ \\
\hline A & $9 \cdot 2 \pm 1 \cdot 8$ & $5 \cdot 8 \pm 0 \cdot 6$ & $13 \cdot 6 \pm 1 \cdot 1$ \\
B & $8 \cdot 3 \pm 1 \cdot 8$ & $6 \cdot 2 \pm 1 \cdot 1$ & $13 \cdot 9 \pm 1 \cdot 9$ \\
C & $6 \cdot 2 \pm 1 \cdot 1$ & $5 \cdot 4 \pm 0 \cdot 5$ & $13 \cdot 0 \pm 1 \cdot 0$ \\
& Statistical comparisons & \\
A v B & NS & NS & NS \\
B v C & NS & NS & NS \\
A v C & NS & NS & NS \\
\hline
\end{tabular}

of linoleic acid in the three groups studied, nor was there any significant difference in the intake of linoleic acid as a percentage of total fat or of unsaturated fatty acids.

Table 7 shows the intake of total calories, protein, and carbohydrate of the healthy subjects and the ill patients. The intake of calories, protein, and carbohydrate was significantly reduced in all of the ill groups when compared with healthy controls; the lowest intake occurring in acute non-neurological illness. There was no significant difference in multiple sclerosis when compared with acute non-neurological illness or with neurological controls, or when neurological
TABLE 7

DAILY INTAKE OF CALORIES, PROTEIN, AND CARBOHYDRATES FOR ALL GROUPS STUDIED

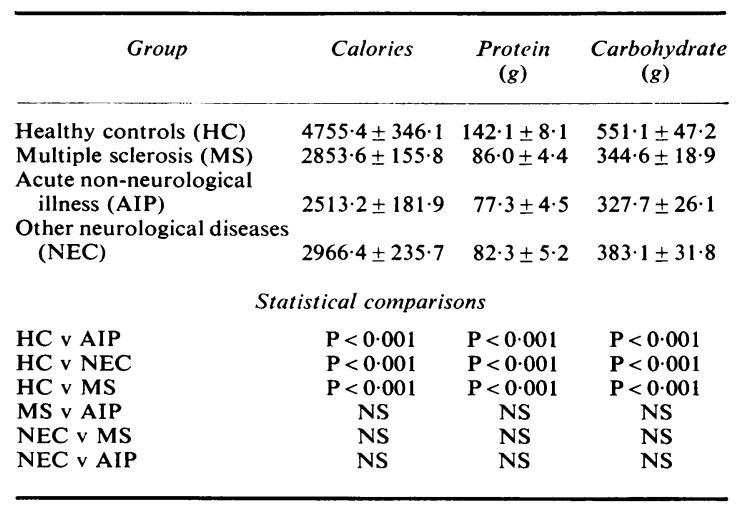

controls were compared with acute nonneurological illness.

Table 8 shows the intake of calories, protein, and carbohydrate in multiple sclerosis during various phases of activity of the disease. The highest intake was found in patients with exacerbations of the disease and the lowest intake in those permanently confined to bed or to a wheelchair.

\section{DISCUSSION}

As shown in Table 5, the intake of linoleic acid in multiple sclerosis is not significantly different from that of healthy controls or the other groups studied. Furthermore, when linoleic acid

\section{TABLE 8}

DAILY INTAKE OF CALORIES, PROTEIN, AND CARBOHYDRATE IN MULTIPLE SCLEROSIS IN RELATION TO ACTIVITY OF THE DISEASE

\begin{tabular}{cccc}
\hline Group & Calories & $\begin{array}{c}\text { Protein } \\
(\mathrm{g})\end{array}$ & $\begin{array}{c}\text { Carbohydrate } \\
(\mathrm{g})\end{array}$ \\
\hline A & $3464 \cdot 9 \pm 321 \cdot 2$ & $105 \cdot 9 \pm 9 \cdot 7$ & $426 \cdot 8 \pm 35 \cdot 9$ \\
B & $2722 \cdot 7 \pm 242 \cdot 9$ & $77 \cdot 8 \pm 6 \cdot 0$ & $230 \cdot 9 \pm 31 \cdot 0$ \\
C & $2522 \cdot 8 \pm 215 \cdot 0$ & $79 \cdot 9 \pm 6 \cdot 5$ & $307 \cdot 3 \pm 24 \cdot 9$ \\
& Statistical comparisons & \\
A v B & NS & NS & NS \\
B v C & NS & NS & NS \\
A v C & NS & NS & P $<0.01$ \\
\hline
\end{tabular}


is expressed as a percentage of total fat intake or as a percentage of unsaturated fatty acid intake, there was no significant difference in the intake of the multiple sclerosis group. Therefore, in multiple sclerosis, linoleic acid intake is not decreased either in absolute or relative terms. We have, however, confirmed the findings of Baker et al. (1964) that serum linoleate is significantly decreased in patients with multiple sclerosis (Love et al., 1972). Since, however, Belin et al. (1971) have shown that the absorption of linoleic acid is not altered in multiple sclerosis it seems that the defect in linoleate metabolism in multiple sclerosis is not related to a dietary deficiency or a defect in absorption. The suggestion of Thompson (1966) that a reduction in the level of serum linoleic acid in multiple sclerosis could be due to an increase in saturated fat intake or a decrease in the unsaturated fat intake seems unlikely in view of the results reported here.

A significant reduction in linoleic acid intake was found only in acute non-neurological illness. It was worth noting that the most significant decrease in serum linoleate also occurred in this group (Love et al., 1972), which suggests that the dietary intake may play some part in the reduced serum linoleic acid in this group. However, the average daily intake in acute non-neurological illness is $4.7 \mathrm{~g}$ of linoleate which is $1.7 \%$ of total calories. This is well above the minimum linoleate requirement to maintain normal levels of dienoic, trienoic, and tetraenoic acids in serum lipids (Wiese, 1971). Previous dietary studies in multiple sclerosis have not given any quantitative data. Brickner and Brill (1940) gave qualitative data only, while McAlpine and Compton(1952) concluded that the dietary intake in multiple sclerosis did not differ from that of sedentary workers. Quantitative data were not given. When correlating changes in the incidence of the disease in Norway, Denmark and Holland, Swank (1950a) based his observations on the amount of fat available at that time, and the dietary studies carried out in Norway (Swank et al., 1952) did not provide any quantitative data on multiple sclerosis patients. Our study shows that the intake of protein, fat, carbohydrate, and calories is reduced in multiple sclerosis with a further reduction in intake as the patient becomes more disabled due to the disease. The higher intake in patients in acute exacerbations was probably related to the relatively mild disability before the onset of the exacerbation, the dietary study having been taken within one week of admission to hospital. The dietary intake, however, was adequate for sedentary workers and no deficiency of food intake was noted. The decrease in the intake of food, however, was not specific for multiple sclerosis, but was due to illness as it was found in other ill patients. Although the fat intake in the control group suggested that multiple sclerosis occurred in an area of high fat intake, no definite association between the pathogenesis of multiple sclerosis and dietary fat could be concluded from this study. The reduction in the intake of fat which was noted with progressive disability did not appear to halt the progress of the disease, although the intake was higher than the amount used by Swank (1953, 1955, 1956; Swank and Bourdillon, 1960; Swank, 1970) for the treatment of this disease.

The calorie intake of the control group was ato a very high level and corresponded with the calorie requirements recommended for people $\stackrel{\square}{\mathbb{Q}}$ involved in hard work in very cold climates (Davidson and Passmore, 1966). It undoubtedly represents an intake of food in excess of require ments for the groups studied. The Food ando Agricultural Organisation/World Health Organ- $-\frac{\overrightarrow{+}}{\omega}$ isation mission (1965) showed that, among the European countries studied, Ireland had the highest average calorie supplies per head of population with an average of 3,400 calories available, compared with an estimated requirement of 2,620 calories. The intake of calories, protein, carbohydrate, and fat was much higher than the areas studied in Norway by Swank et al. (1952). No data are available on the prevalence of multiple sclerosis in the Republic of Ireland to compare with the dietary habits, although data available from Northern Ireland (Allison and Millar, 1954) suggest that Ireland as a whole is probably a high prevalence area.

We gratefully acknowledge the help given by the Medical Research Council of Ireland, The Multiple Sclerosis Society of Ireland, and by Dr. O'Regan and Miss Horgan, of the Computer Science Department, University College, Cork. 


\section{REFERENCES}

Allison, R. S. (1963). Some neurological aspects of medical geography. Proceedings of the Royal Society of Medicine, 56, 71-76.

Allison, R. S., and Millar, J. H. D. (1954). Prevalence and familial incidence of disseminated sclerosis. Ulster Medical Journal, 23, Suppl. 2.

Alter, M., Halpern, L., Kurland, L. T., Bornstein, B., Leibowitz, U., and Silberstein, J. (1962). Multiple sclerosis in Israel. Prevalence among immigrants and native inhabitants. Archives of Neurology, 7, 253-263.

Baker, R. W. R., Thompson, R. H. S., and Zilkha, K. J. (1964). Serum fatty acids in multiple sclerosis. Journal of Neurology, Neurosurgery, and Psychiatry, 27, 408-414.

Belin, J., Pettet, N., Smith, A. D., Thompson, R. H. S., and Zilkha, K. J. (1971). Linoleate metabolism in multiple sclerosis. Journal of Neurology, Neurosurgery, and Psychiatry, 34, 25-29.

Brickner, R. M., and Brill, N. Q. (1941). Dietetic and related studies in multiple sclerosis. Archives of Neurology and Psychiatry, 16, 35.

Brunner, D., and Lobl, K. (1958). Serum cholesterol, electrophoretic lipid pattern, diet and coronary artery disease: a study in coronary patients and in healthy men of different origin and occupations in Israel. Annals of Internal Medicine, 49, 732-750.

Davidson, S., and Passmore, R. (1966). Human Nutrition and Dietetics. 3rd edn., pp. 25, 672, and 790. Livingstone: Edinburgh.

Demole, M. (1943). Alimentation militaire (1942). Schweizerische medizinische Wochenschrift, 73, 827-831.

Food and Agriculture Organization/World Health Organization Mission (1965). Nutrition Education in Six Western European Countries. FAO: Rome.

Gul, S., Smith, A. D., Thompson, R. H. S., Wright, H. P. and Zilkha, K. J. (1970). The fatty acid composition of phospholipids from platelets and erythrocytes in multiple sclerosis. Journal of Neurology, Neurosurgery, and Psychiatry, 33, 506-510.

Love, W. C., Cashell, A., Reynolds, M., and Callaghan, N. (1972). Serum linoleic acid and fatty acid pattern in multi- ple sclerosis and acute illness. In 8th International Congress of Clinical Chemistry, Copenhagen, 1972. Abstracts of Papers. 3.48. Scandinavian Journal of Clinical and Laboratory Investigation, 29, Suppl. 126.

McAlpine, D., and Compston, N. (1952). Some aspects of the natural history of disseminated sclerosis. Quarterly Journal of Medicine, 21, 135-167.

McAlpine, D., Lumsden, C. E., and Acheson, E. D. (1965). Multiple Sclerosis. A Reappraisal, p. 34-35. Livingstone: Edinburgh.

McCance, R. A., and Widdowson, E. M. (1960). The Composition of Foods. Medical Research Council. Special Report Series, No. 297. H.M.S.O.: London.

Swank, R. L. (1950). Multiple sclerosis: a correlation of its incidence with dietary fat. American Journal of Medical Sciences, 220, 421-430.

Swank, R. L., Lerstad, O., Strøm, A., and Backer, J. (1952) Multiple sclerosis in rural Norway. New England Journal of Medicine, 246, 721-728.

Swank, R. L. (1953). Treatment of multiple sclerosis with low-fat diet. Archives of Neurology and Psychiatry, 69, 91-103.

Swank, R. L. (1955). Treatment of multiple sclerosis with low-fat diet. Result of five and one-half years' experience. Archives of Neurology and Psychiatry, 73, 631-644.

Swank, R. L. (1956). Treatment of multiple sclerosis with low-fat diet. Result of seven years' experience. Annals of Internal Medicine, 45, 812-824.

Swank, R. L. (1970). Multiple sclerosis: twenty years on low fat diet. Archives of Neurology (Chicago), 23, 460-474.

Swank, R. L., and Bourdillon, R. B. (1960). Multiple sclerosis: assessment of treatment with a modified low-fat diet. Journal of Nervous and Mental Diseases, 131, 468-488.

Thompson, R. H. S. (1966). A biochemical approach to the problem of multiple sclerosis. Proceedings of the Royal Society of Medicine, 59, 269-276.

Watt, B. K., and Merrill, A. L., (1963). Composition of foods. Agriculture Handbook No. 8, pp. 122-145. United States Department of Agriculture: Agricultural Research Service, Washington.

Wiese, H. F. (1971). Essential fatty acids. Deficiency effects in human beings. In The Vitamins, Vol. 3, pp. 327-335. 2nd edn. Edited by W. H. Sebrell, Jr., and R. S. Harris. Academic Press: New York. 